\title{
Synthesis and characterisation of CZTSe bulk materials for thermoelectric applications
}

\author{
Yogeshchandra Sharma \\ Department of Physics, Vivekananda Global University, Jaipur-303012, Rajasthan, India \\ yc.sharma.vit@gmail.com, \\ +919664075093, +917597776818, https://orcid.org/0000-0003-3532-6097
}

PACS 85.80.Fi, 72.20.Pa, 72.20.My, 82.80.Gk, 82.80.Pv, 61.05.cp, 74.25.Fy

DOI 10.17586/2220-8054-2020-11-2-195-204

Quaternary Copper Zinc Tin Selenide (CZTSe) is a preferred candidate as an absorber layer in solar cells due to its non-toxicity and the abundancy of its constituents. This material also has thermoelectric properties suitable for solar thermal energy conversion and waste heat recovery. The preparation of bulk thermoelectric materials is a tedious, multistep task and requires considerable time and energy consumption for tuning of desired properties. Here one step solid state reaction has been used for synthesis of bulk CZTSe materials in five different ratios of elemental precursors: $\mathrm{Cu}, \mathrm{Zn}, \mathrm{Sn}$ and Se. Atomic Force Microscopy (AFM), X-Ray Photoelectron Spectroscopy (XPS) and X-ray diffraction (XRD) techniques have been used for structural and compositional analysis of the materials. AFM analysis shows significant difference in roughness parameters and grain size with respect to $\mathrm{Cu} / \mathrm{Zn}$ variations. The XRD spectra of various samples show the formation of CZTSe materials. Raman spectra verifies absence of secondary phases. XPS analysis reveals constituent atoms display chemical valences of $+1,+2,+4$, and $-1 \mathrm{for} \mathrm{Cu}, \mathrm{Zn}, \mathrm{Sn}$, and $\mathrm{Se}$, respectively. The stoichiometric sample, $\mathrm{Cu}_{2} \mathrm{ZnSnSe}_{4}$, exhibited the maximum power factor $0.30 \mathrm{~mW} \cdot \mathrm{m}^{-1} \mathrm{~K}^{-2}$, having carrier concentration in the range of $10^{18}-10^{19} \mathrm{~cm}^{-3}$ and resistivity in the range of 0.21 to $0.24 \Omega \cdot \mathrm{cm}$.

Keywords: thermoelectric devices, thermoelectric effects in semiconductors and insulators, Hall effect in semiconductors, Raman spectroscopy in chemical analysis, photoelectron spectroscopy in chemical analysis, powder diffraction X-ray, transport properties (electric and thermal conductivity, thermoelectric effects, etc.).

Received: 20 December 2019

Revised: 28 February 2020

\section{Introduction}

The use of thermoelectric technology will increase as it can build solid state devices having better reliability and power density. In future, it will be main technology behind the sustainable energy applications which will be able to overcome ever growing energy demand and depleting fossil fuels. Although, most high performance thermoelectric materials are tellurides or antimonides but these contain toxic and rare earth elements. Higher cost and toxicity are major issues which are hindering the wide use of thermoelectric devices in areas like household heating and cooling, medical applications and automobiles. Besides the discovery of new materials it is sometimes of interest to investigate known materials that show promise in different domains; like quaternary chalcogenides, which are composed of earth abundant materials and have been studied for a variety of different applications like, solar-cell absorbers [1-3], photocatalysts for solar water splitting [4], nonlinear optics [5], topological insulators [6], and magneto-optic and magneto-ferroics [7,8]. In these materials, the transport of carriers is often disturbed and impeded by grain boundaries and the interfaces between the matrix and composites. Recently, certain multinary compounds like, CZTS, CZTSe and others have attracted great interest as thermoelectric materials because their physical properties can be tuned by varying the elemental composition.

For a thermoelectric material, the energy conversion efficiency, $Z T=S^{2} T / k$, where $T$ is the absolute temperature, $S$ is the Seebeck coefficient, $\sigma$ is the electrical conductivity, and $\kappa$ is the thermal conductivity which consists of electronic thermal conductivity $\left(\kappa_{e}\right)$ and lattice thermal conductivity $\left(\kappa_{L}\right)$. Simultaneous increase of $\sigma$ and reduction of $\kappa$ are preferred for the $Z T$ enhancement but these factors have trade-off relationship with each other.

Conventional TE materials are narrow band gap semiconductors in which a bipolar effect may reduce the TE efficiency [9]. The TE properties of quaternary chalcogenides CZTS, CZTSe, $\mathrm{Cu}_{2} \mathrm{ZnGeSe}_{4}, \mathrm{Cu}_{2} \mathrm{CdSnSe}_{4}$ and $\mathrm{Cu}_{2} \mathrm{FeSnS}_{4}$ have been studied by various workers [10-20]. Their band gaps are wide enough to avoid the bipolar effect and these have low thermal conductivities due to the complexity of the crystallographic structures; this enables them to be a potentially outstanding class of TE materials. Although the $Z T$ values obtained for these are still about 0.9 , these are still lower than those for ternary compounds. It has been reported that for quaternary materials, relatively low thermal conductivity and good electrical properties could be achieved by appropriate doping [21-24]. It has been reported by various workers that modification of electrically conducting units by doping of $\mathrm{Cu}^{2+}$ create more hole carriers and 
extra conducting pathways [25-27]. The structural disruption through doping units effectively enhances the $\sigma$ values without significantly affecting the electrical thermal conductivity, which ultimately enhances the $Z T$ value. The experiments have further shown that the total thermal conductivity of $\mathrm{Cu}$-based quaternary chalcogenides with chalcopyrite derived structures is very low as compared to well-optimized TE material like $\mathrm{Bi}_{2} \mathrm{Te}_{3}$ alloy. This is due to the fact that the total thermalconductivity in these compounds is dominated mainly by phonon thermal conductivity than electrical thermal conductivity, along with a possibility of random distribution of cations and anions in the unit cell, which may gave rise to structural anisotropy, responsible for lowering of thermal conductivity. Similar studies have been reported for other structural forms of these quaternary chalcogenides such as wurtzite, orthorhombic, stannite and stannite-kuramite etc. [28-31].

Similar electronic behavior as well as transport properties have been observed as a function of temperature, doping level and crystal symmetry for CZTX $(\mathrm{X}=\mathrm{S}$, Se and Te), imparting similar thermoelectric behavior in all three. The results obtained in the reports give a way to explore high performance thermoelectric materials with the family of widely existing tetrahedrally bonded semiconductors. Among these materials CZTSe has been explored as high performance thermoelectric material with $Z T$ value of 0.28 at $700 \mathrm{~K}$ by Shi et al [32], which further improves to 0.95 at $850 \mathrm{~K}$ by indium doping in the material $\mathrm{Cu}_{2} \mathrm{ZnSn}_{0.90} \mathrm{In}_{0.10} \mathrm{Se}_{4}$, owing to the lower thermal conductivity of the doped material. The work by $\mathrm{Chen}$ et al [33] on Cu-doped CZTSe polygon like nanocrystals suggests that, the substitution of $\mathrm{Zn}^{2+}$ with $\mathrm{Cu}^{+}$while $\mathrm{Cu}$-doping introduces extra holes as charge carrier in CZTSe, which enhances the electrical conductivity. On the other hand, the intensive phonon scattering at the small grain boundaries of the polygon shaped nanocrystals reduces the thermal conductivity.

CZTSe has a band gap in the range of $1.4-1.5 \mathrm{eV}$, also has thermoelectric properties useful in energy conversion technologies. A number of methods have been used for the synthesis of CZTSe thin films and bulk materials, like Aqueous Synthesis method [34], RF-DC sputtering method [35, 36], thermal co-evaporation [37], electro deposition method [38], Molecular beam epitaxy [39] and solid state reaction [40-51] etc.

In this work, CZTSe bulk materials have been synthesised by one step solid state reaction of its elemental constituents at $850{ }^{\circ} \mathrm{C}$ in a rocking furnace. This approach that has proven successful for other chalcogenide materials, herein the synthesis and study of structural properties have been reported. The materials are analyzed for formation of CZTSe along with various phases by AFM, XRD and Raman spectroscopic techniques while uniformity of elemental distribution was analyzed using XPS technique. To understand electrical behavior Hall effect and thermoelectric measurements have also been performed.

\section{Experimental details}

\subsection{Materials synthesis}

Quartz ampoules were etched in acetone and cleaned with DI water for 30 minutes to remove impurities. High purity $\mathrm{Cu}, \mathrm{Zn}, \mathrm{Sn}$ and $\mathrm{Se}(99.99 \%)$ powders were weighed and mixed in an agate mortar according to the stoichiometry reported in Table 1. These were then loaded in five different cleaned quartz ampoules, which were sealed under vacuum at $\sim 1 \times 10^{-6}$ torr. These ampules were then placed one by one in a vertical rocking furnace, in which these were heated to $850{ }^{\circ} \mathrm{C}$ (at a rate of $50{ }^{\circ} \mathrm{C}$ per hour) and then held up for four hours. After cooling down to room temperature the ampoules were broken to extract the solid samples. The bulk materials obtained were grinded again with agate mortar and the process of solid state reaction was repeated for five times. After the completion of fifth cycle these chunks were separated from ampoules. For performing the electrical measurements small parts of the chunks were grinded into square shape and polished. The bulk densities of the samples were measured by employing the Archimedes principle. Stoichiometry variations in the ratio of solid state reacted CZTSe compounds and their densities have been given in the Table 1.

\subsection{XRD analysis}

Crystalline quality and epitaxial nature of bulk materials were determined from XRD measurements, which were performed using the synchrotron beam at angle-dispersive X-ray diffraction (ADXRD) beamline (BL-12) of Indian synchrotron source "Indus-2" at Raja Ramanna Centre for advanced Technology (RRCAT), Indore. Wave length of $0.78765 \AA$ for angle dispersive x-ray diffraction experiments was selected from the white light using a Si (111) channel cut monochromator. The monochromatic beam is then focused on to the sample with a Kirkpatrick-Baez (K-B) mirror. A MAR345 image plate detector (Mar345 area detector with $0.1 \times 0.1 \mathrm{~mm}^{2}$ pixel) was used to collect 2D diffraction data. Sample to detector distance and the wavelength of the beam were calibrated using NIST standards $\mathrm{LaB}_{6}$ and $\mathrm{CeO}_{2}$. 2D diffraction data were then integrated using FIT2D software to get desired $1 \mathrm{D}$ intensity versus $2 \theta$ data. 
TABLE 1. Stoichiometry variations in the ratio of various samples and their bulk densities

\begin{tabular}{|c|c|c|c|c|c|c|}
\hline Sample & Stoichiometry & $\mathrm{Cu} / \mathrm{Zn}$ & $\mathrm{Cu} / \mathrm{Sn}$ & $\mathrm{Se} /(\mathrm{Cu}+\mathrm{Zn}+\mathrm{Sn})$ & $\mathrm{Cu} /(\mathrm{Zn}+\mathrm{Sn})$ & Density $\left(\mathrm{gm} / \mathrm{cm}^{3}\right)$ \\
\hline \hline Sample 1 & $\mathrm{Cu}_{2} \mathrm{ZnSnSe}_{4}$ & 2.0 & 2.0 & 1.0 & 1.0 & 5.67 \\
\hline Sample 2 & $\mathrm{Cu}_{2} \mathrm{ZnSnSe}_{5.6}$ & 2.0 & 2.0 & 1.4 & 1.0 & 5.68 \\
\hline Sample 3 & $\mathrm{Cu}_{2} \mathrm{ZnSnSe}_{5.2}$ & 2.0 & 2.0 & 1.3 & 1.0 & 5.64 \\
\hline Sample 4 & $\mathrm{Cu}_{1.8} \mathrm{ZnSnSe}_{5.2}$ & 1.8 & 1.8 & 1.36 & 0.9 & 5.62 \\
\hline Sample 5 & $\mathrm{Cu}_{2} \mathrm{Zn}_{1.1} \mathrm{SnSe}_{5.2}$ & 1.818 & 2.0 & 1.26 & 0.95 & 5.60 \\
\hline
\end{tabular}

\subsection{Raman analysis}

The Raman spectroscopy measurements were performed at room temperature using a DPSS semiconductor Laser (make: Action spectrapro, sp-2500) as an excitation. The wavelength of the laser is $532 \mathrm{~nm}$, to avoid laser heating the beam power was kept at $15 \mathrm{~mW}$. The monochromator grating used was having 600 lines per mm. The spectra were recorded for 30 seconds at different locations. The lens used was having magnification of $20 \times$. Raman spectra were recorded with a monochromator system in backscattering configuration with a microscope and a motorized XY stage.

\subsection{Atomic force microscopy (AFM) analysis}

The samples were placed on the surface of a nickel disk $\left(1.2 \mathrm{~cm}^{2}\right)$ using double-sided adhesive tape and placed it on the AFM scanner (Multi-Mode/Nanoscope 8 scanning probe microscope, Bruker, USA). Measurements were performed in air under ambient conditions $\left(T=25^{\circ} \mathrm{C}, \mathrm{RH}=21 \%\right)$ using the J-scanner $(\min x y=5 \mu \mathrm{m})$. Scanning was performed in tapping mode using Si cantilevers with integrated tips $(t=3.75 \mu \mathrm{m}, l=125 \mu \mathrm{m}, w=35 \mu \mathrm{m}$, $F_{0}=300 \mathrm{kHz}, k=40 \mathrm{Nm}^{-1}$ ) and an RMS amplitude of $1.5 \mathrm{~V}$. The images were processed and dimensions measured using Nanoscope Analysis software (V9, Bruker).

\subsection{XPS analysis}

$\mathrm{X}$-ray photoelectron spectroscopy measurements were carried using synchrotron radiation facility hard x-ray photoelectron spectroscopy (HAXPES) beamline BL-14, Indus-2 [52] which has double-crystal monochromator [Si (111)] with excitation energy of $4.311 \mathrm{keV}$ and equipped with Hemispherical analyzer and detector system (Phoibos 225 , Specs make). The typical pressure in the experimental station is $5 \times 10^{-9}$ mbar.

\subsection{Electrical measurements}

The electrical conductivity $(\sigma)$ was measured using the four probe set up and the thermoelectric measurement set up.Conductivity measurements were done with the help of Hall set up (HMS 5000 from Ecopia Corp., South Korea) at room temperature (RT) with a 0.5T magnetic field in the van der Pauw configuration. The HMS-5000 Hall Measurement System is a complete system for measuring the carrier concentration, carrier mobility $(\mu)$ and resistivity of materials. The HMS-5000 includes software with current-voltage curve capability for checking the ohmic integrity of the user made sample contacts.

\subsection{Thermoelectric measurements}

The setup for measuring Seebeck coefficient of thermoelectric materials is a designed sample holder, which consists two cuboid shaped copper blocks mounted on a rectangle shaped copper block with top cylinder shaped for temperature dependent measurements (shown in Fig. 1 below). For Seebeck coefficient measurement the sample is placed on two cuboid shaped copper blocks and the sample bridges the two blocks. The heater is used to generate the temperature gradient along the sample, the two PT100 devices have been connected to temperature controller are used to measure the temperature of the copper blocks; these are inserted into the holes provided in copper blocks. The voltage generated as a result of temperature gradient is determined by taking out the two separated contacts on the sample. The setup can measure Seebeck coefficient of both bulk and thin film thermoelectric materials up to a wide range of temperature (RT to $300{ }^{\circ} \mathrm{C}$ ). The process of measurement can also be done in high vacuum, for that the whole system of sample holder is placed in a cylinder shaped case of steel provided with vacuum valve and vacuum lock at the top end. The vacuum arrangement consists of rotary pump and diffusion pump which can create vacuum. The measurements on copper and silicon were measured accurately hence confirms the reliability of the setup. 


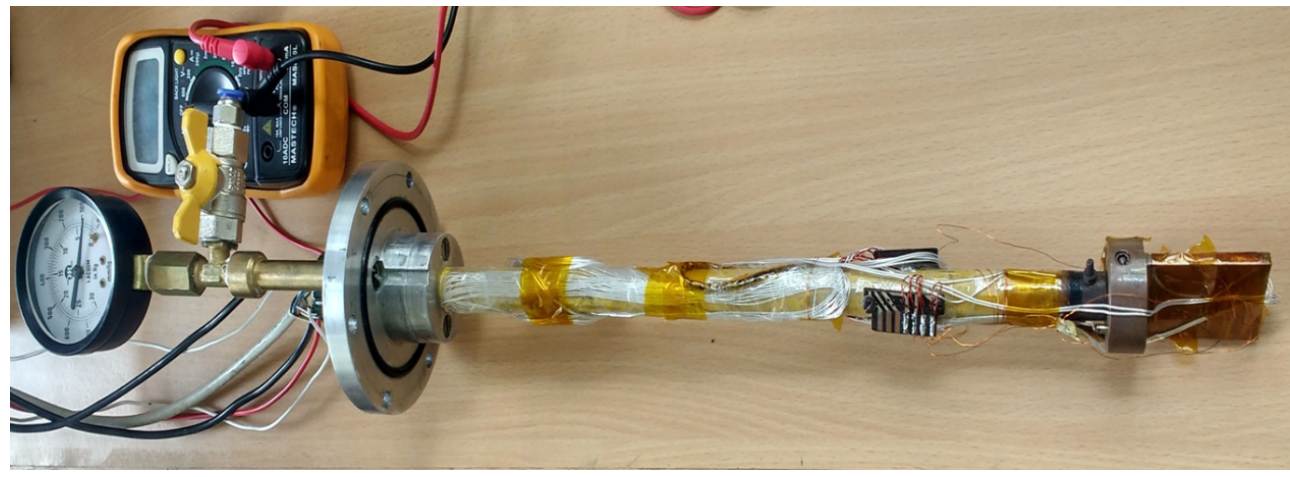

FIG. 1. Various parts of the thermoelectric measurement set up developed in our laboratory

\section{Results and discussion}

\subsection{XRD analysis}

From the XRD results, it has been found that the reaction among the elemental powders $(\mathrm{Cu}, \mathrm{Zn}, \mathrm{Sn}$, and $\mathrm{Se})$ occurred. A possible reason for the reaction is the melting of reactant powders. During the solid state reaction, the maximum reaction temperature $\left(850{ }^{\circ} \mathrm{C}\right)$ is much higher than the melting points of $\mathrm{Zn}\left(420{ }^{\circ} \mathrm{C}\right)$, Sn $\left(232{ }^{\circ} \mathrm{C}\right)$, and Se $\left(221^{\circ} \mathrm{C}\right)$. In this case as the reaction temperature is very high most reactants occur as liquid. The availability of the liquid phases increases the contacting area among different intermediate species formed and facilitates the mass transportation. Mixing at high temperature increases the reaction rate and well mixing of different constituents is obtained.

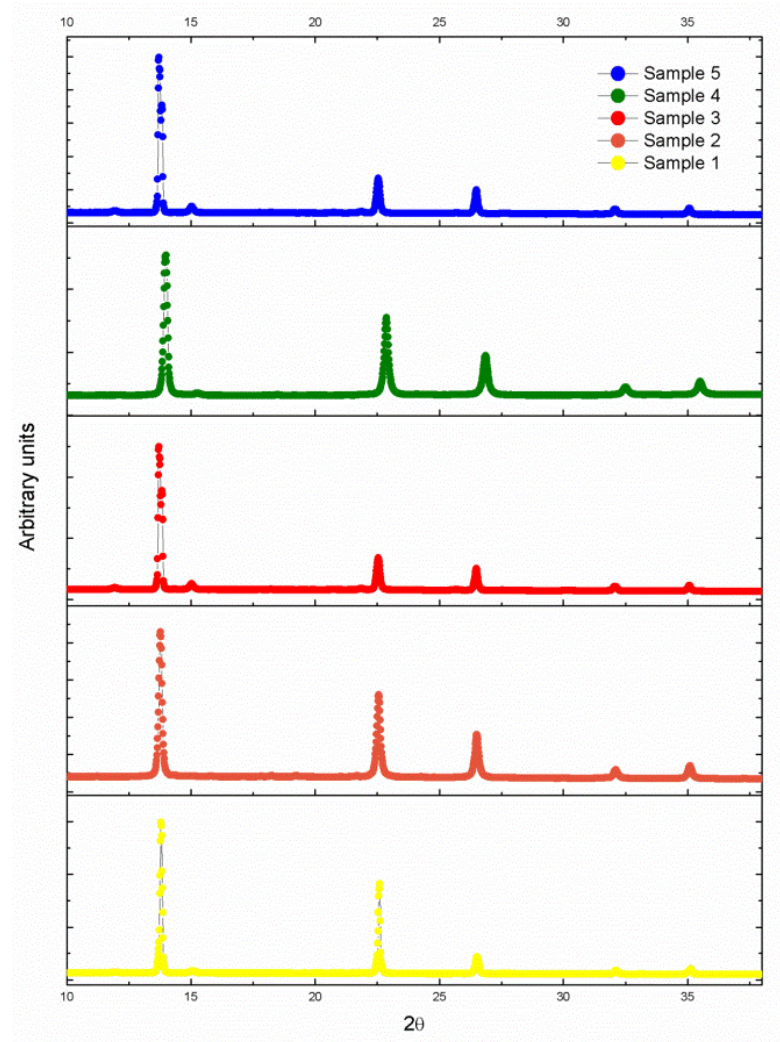

FIG. 2. XRD plots of various samples

The XRD pattern for the Bulk materials synthesized has been shown in Fig. 2. The appearance of prominent peaks confirm the formation of nanocrystalline CZTSe material. Average crystallite size obtained for the different 
materials have been shown in the third column of the Table 2. The crystallite size were calculated from the FWHM for the peaks at various angles $(2 \theta)$ namely, at $13.77,22.56,26.51$ and $32.11^{\circ}$ which corresponds to the reflections from (112), (204), (312) and (316) planes, respectively. A significant variation in the values of crystallite size from 16 to $34 \mathrm{~nm}$ have been seen in the samples which may be due to variation in the stoichiometry's of various sample. All the peaks in the XRD data were indexed with reference to the standard data for the CZTSe compound ICDD file No. 04-003-8817.

TABLE 2. Crystallite size of various samples by XRD data

\begin{tabular}{|c|c|c|}
\hline Sample & Stoichiometry & Crystallite size (nm) \\
\hline \hline Sample 1 & $\mathrm{Cu}_{2} \mathrm{ZnSnSe}_{4}$ & 31 \\
\hline Sample 2 & $\mathrm{Cu}_{2} \mathrm{ZnSnSe}_{5.6}$ & 24.9 \\
\hline Sample 3 & $\mathrm{Cu}_{2} \mathrm{ZnSnSe}_{5.2}$ & 33.6 \\
\hline Sample 4 & $\mathrm{Cu}_{1.8} \mathrm{ZnSnSe}_{5.2}$ & 18.1 \\
\hline Sample 5 & $\mathrm{Cu}_{2} \mathrm{Zn}_{1.1} \mathrm{SnSe}_{5.2}$ & 15.8 \\
\hline
\end{tabular}

\subsection{Raman analysis}

Because the main three diffractions of CZTSe have Bragg angles similar to those of the diffractions of ZnSe and CTSe, it is necessary to investigate the samples by Raman spectroscopy. Figure 3 shows the Raman spectra of various samples in which the vibration modes corresponding CZTSe are present at 191, 217 and $246 \mathrm{~cm}^{-1}$, revealing no secondary phases, such as $\mathrm{Cu}_{2} \mathrm{SnSe}_{3}$ with a tetragonal or cubic structure, and very similar lattice constants to those of CZTSe. The peaks of tetragonal $\mathrm{Cu}_{2} \mathrm{SnSe}_{3}$ appear at $178 \mathrm{~cm}^{-1}$, corresponding to the CZTSe A1-mode; however, no distinct peaks appear at 204, 231 and $291 \mathrm{~cm}^{-1}$ corresponding to A2-mode of $\mathrm{Cu}_{2} \mathrm{SnSe}_{3}$. Also, no major $\mathrm{ZnSe}$ peaks - which would appear at 206 and $252 \mathrm{~cm}^{-1}$, and no other possible secondary phases appear, such as $\mathrm{Cu}-\mathrm{Se}-$ and $\mathrm{Sn}-\mathrm{Se}$-related compounds.

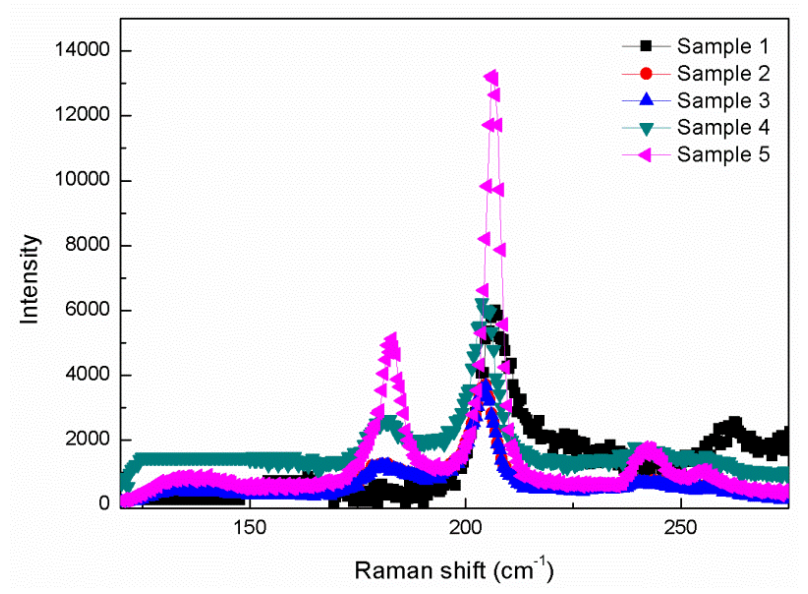

FIG. 3. Raman spectra of various samples

\subsection{AFM analysis}

Atomic force microscopic analysis is ideal for quantitatively measuring the nanometric dimensional surface roughness and for visualizing the surface nano-texture of the materials prepared. Three-dimensional (3D) AFM images of the five different materials have been shown in Fig. 4.

Roughness is the key feature in application of photovoltaic technology as physical and chemical properties are directly affected by this parameter. A small variation in value of average roughness of five different sample of CZTSe is observed with respect to their stoichiometry change. Sample 2 with ratio $\mathrm{Se} /(\mathrm{Cu}+\mathrm{Zn}+\mathrm{Sn})=1.4$ i.e. $\mathrm{Cu}_{2} \mathrm{ZnSnSe}_{5.6} \mathrm{with}$ 

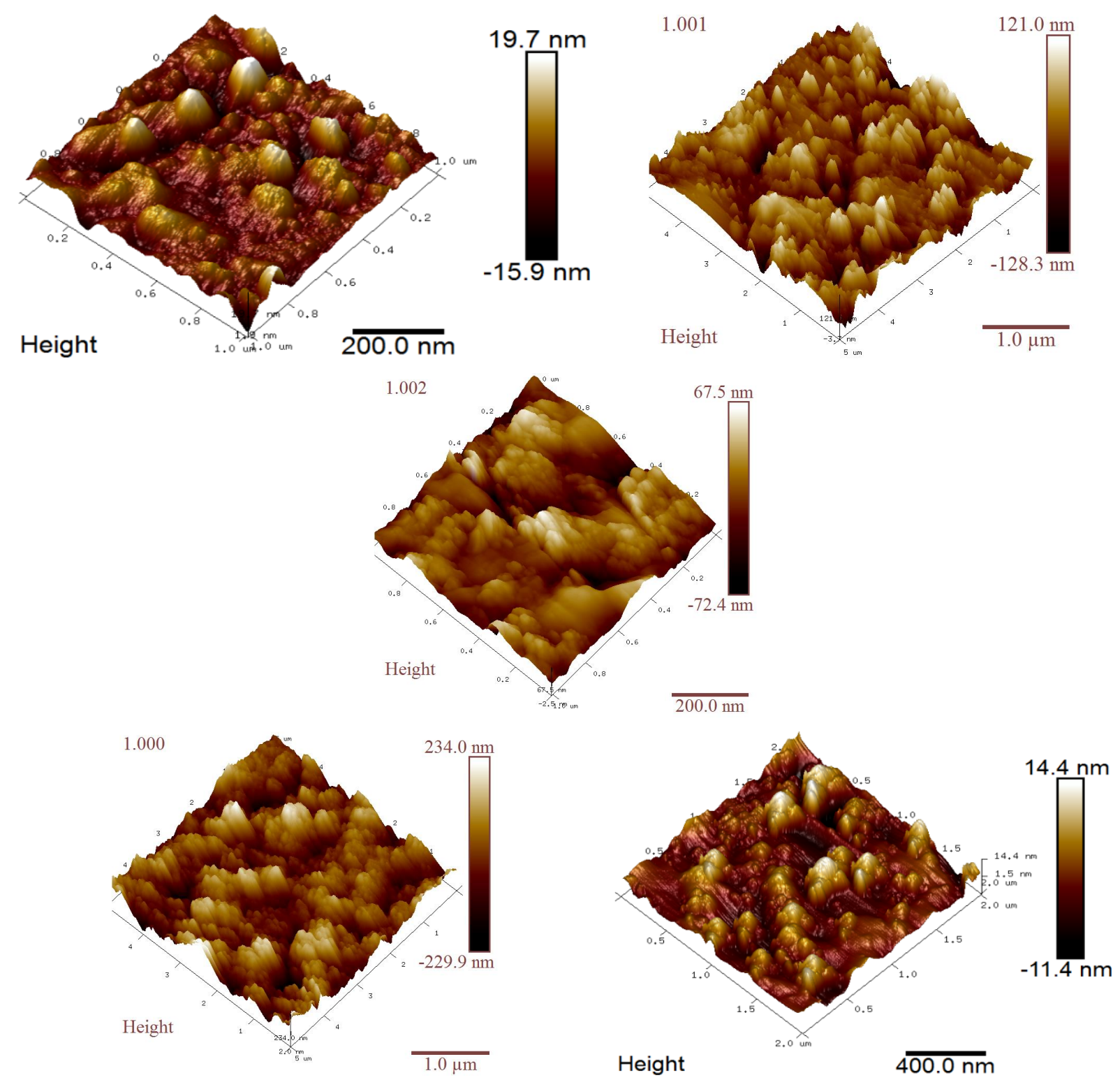

FIG. 4. Three-dimensional (3D) AFM images of various samples

TABLE 3. Roughness parameters of various samples

\begin{tabular}{ccccccc}
\hline Sample ID & $\begin{array}{c}R_{a} \\
(\mathrm{~nm})\end{array}$ & $\begin{array}{c}R_{q} \\
(\mathrm{~nm})\end{array}$ & $\begin{array}{c}R_{z} \\
(\mathrm{~nm})\end{array}$ & $R_{k u} / R_{a}$ & $R_{k u}$ & $R_{s k}$ \\
\hline Sample 1 & 51.8 & 65.24 & 650 & 1.259 & 6.02 & 0.932 \\
Sample 2 & 49.4 & 63.8 & 636 & 1.2914 & 3.41 & 0.105 \\
Sample 3 & 51.8 & 65.1 & 427 & 1.2561 & 2.88 & 0.0750 \\
Sample 4 & 51.1 & 64.8 & 521 & 1.2681 & 3.01 & 0.0542 \\
Sample 5 & 50.9 & 64.2 & 590 & 1.2612 & 3.17 & 0.0458 \\
\hline
\end{tabular}


$40 \%$ excess of Se exhibits the lowest value of average roughness $49.4 \mathrm{~nm}$ while Sample 1 with perfect stoichiometry $\mathrm{Cu}_{2} \mathrm{ZnSnSe}_{4}$ and Sample 3 with $30 \%$ excess of $\mathrm{Se}, \mathrm{Cu}_{2} \mathrm{ZnSnSe}_{5.2}$ exhibited same value of roughness $51.8 \mathrm{~nm}$. Table 3 illustrates that the variations in RMS roughness $\left(R_{q}\right)$ values observed for all CZTSe samples are exactly have the same trend as exhibited by average roughness values $\left(R_{a}\right)$ and ten point mean height $R_{z}$ values.

\subsection{XPS analysis}

Figure 5 shows the XPS spectra of all the samples synthesized. The $\mathrm{Cu} 2 \mathrm{p}$ spectrum shows two narrow symmetric peaks at $932 \mathrm{eV}\left(2 \mathrm{p}^{3 / 2}\right)$ and $952 \mathrm{eV}\left(2 \mathrm{p}^{1 / 2}\right)$ with a peak splitting of $20 \mathrm{eV}$, which is characteristic of $\mathrm{Cu}$ (I). The $\mathrm{Zn} 2 \mathrm{p}$ peaks appearing at $1021 \mathrm{eV}\left(2 \mathrm{p}^{3 / 2}\right)$ and $1044 \mathrm{eV}\left(2 \mathrm{p}^{1 / 2}\right)$ with a peak splitting of $23 \mathrm{eV}$ correspond to $\mathrm{Zn}$ (II). The $\mathrm{Sn}$ $3 \mathrm{~d}$ peaks appearing at $486 \mathrm{eV}\left(3 \mathrm{~d}^{5 / 2}\right)$ and $495 \mathrm{eV}\left(3 \mathrm{~d}^{3 / 2}\right)$ with a peak splitting of $9 \mathrm{eV}$ can be assigned to Sn (IV). The Se $3 p$ peaks appearing at $160 \mathrm{eV}\left(3 \mathrm{p}^{3 / 2}\right)$ and $166 \mathrm{eV}\left(3 \mathrm{p}^{1 / 2}\right)$ with a peak splitting of $6 \mathrm{eV}$ can be assigned to Se (IV) indicates Se with a valence of -1 . Similar XPS spectra were observed for all the samples, confirming the chemical valence of $+1,+2,+4$, and -1 for $\mathrm{Cu}, \mathrm{Zn}$, Sn, and Se, respectively.
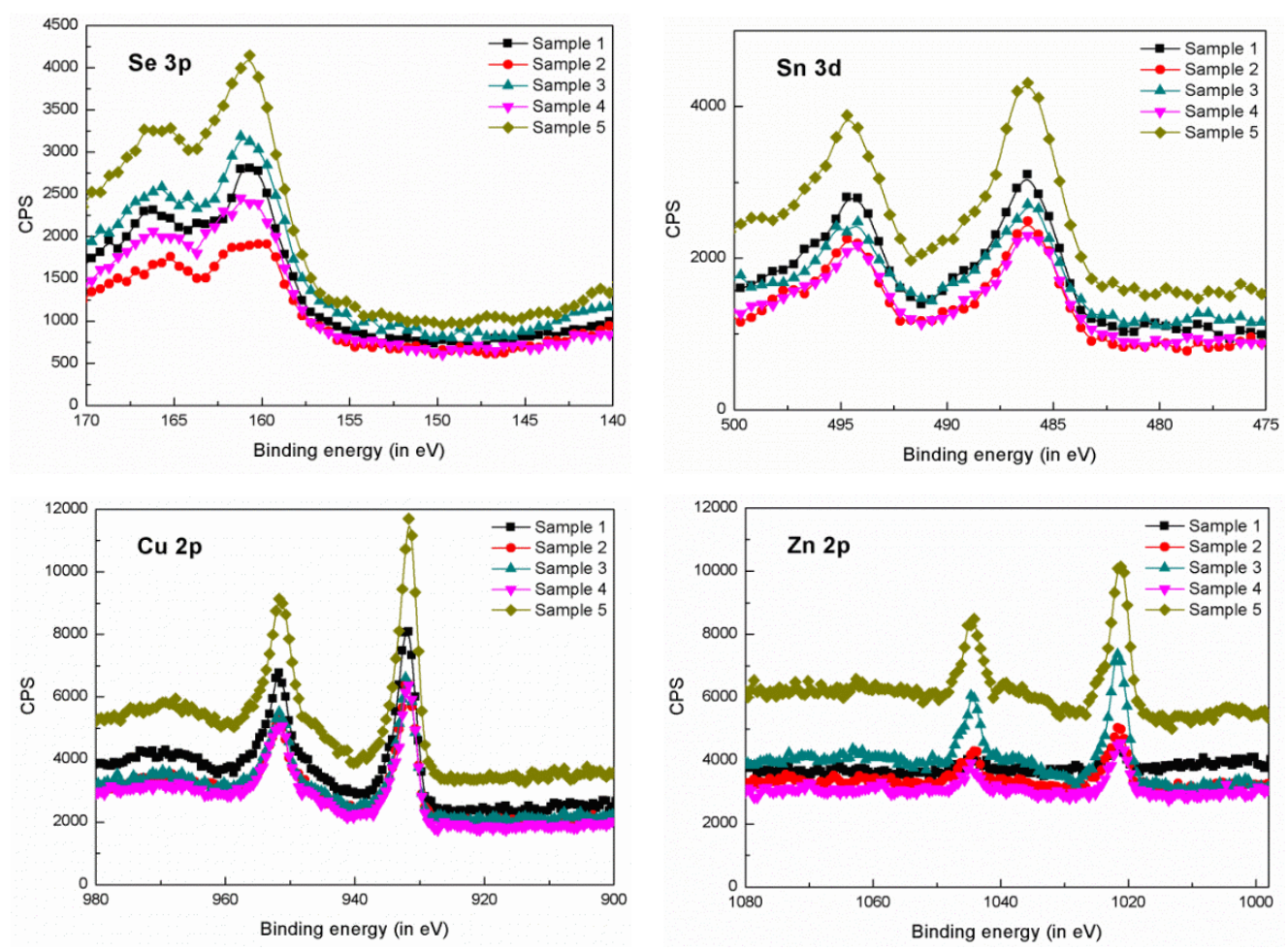

FIG. 5. XPS core level peaks of various samples

\subsection{Electrical measurements}

The electrical transport properties of the synthesized bulk materials are measured in the temperature range of $300-600 \mathrm{~K}$. The electrical conductivities of the samples fall in the ranges of $12500-16000 \mathrm{~S} \cdot \mathrm{m}^{-1}$ and $4200-$ $4800 \mathrm{~S} \cdot \mathrm{m}^{-1}$ at 300 and $600 \mathrm{~K}$, respectively. For all the samples, the electrical conductivity decreases the exact reason for this transition of the $\sigma-\mathrm{T}$ dependence is unknown to author at present. Among the materials, the $\mathrm{Cu}$-excessive sample $\left(\mathrm{Cu}_{2} \mathrm{ZnSnSe}_{4}\right)$ shows the largest electrical conductivity, in the temperature range $300-600 \mathrm{~K}$. This behavior may be attributed to the creation of holes $\left(\mathrm{Cu}^{2+} 3 \mathrm{~d}^{9}\right.$ vs. $\left.\mathrm{Cu}^{+} 3 \mathrm{~d}^{10}\right)$ and the conversion of electrically insulating paths to electrically conducting paths. As reported by some workers, the electrical conductivity is little changed in Se excess doping, it has been observed that with increase in the Se content electrical conductivity decreases, having a minimum value of $4200 \mathrm{~S} \cdot \mathrm{m}^{-1}$ for the $\mathrm{Cu}_{1.8} \mathrm{ZnSnSe}_{5.2}$ stoichiometry. The synthesized bulk materials exhibit positive Seebeck coefficients, confirming their p-type character. The Seebeck coefficients of the samples increase with increasing temperature, having the values in the ranges of $40-55 \mu \mathrm{V} \cdot \mathrm{K}^{-1}$ and $185-250 \mu \mathrm{V} \cdot \mathrm{K}^{-1}$ at 300 and $600 \mathrm{~K}$, respectively. By comparing the five samples, it has been found that both $\mathrm{Cu}$-excess and Se-excess lead to an enhancement of Seebeck coefficients. With high electrical conductivity and large Seebeck coefficient, the $\mathrm{Cu}$-excessive sample $\left(\mathrm{Cu}_{2} \mathrm{ZnSnSe}_{4}\right)$ exhibits the maximum power factor in the whole temperature range, which reaches $0.30 \mathrm{~mW} \cdot \mathrm{m}^{-1} \mathrm{~K}^{-2}$ at $600 \mathrm{~K}$. 
The stoichiometric sample $\mathrm{Cu}_{2} \mathrm{ZnSnSe}_{4}$, shows highest power factor while the $\mathrm{Cu}$-deficient sample, $\mathrm{Cu}_{1.8} \mathrm{ZnSnSe}_{5.2}$, shows the lowest power factor at highest temperature $600 \mathrm{~K}$. The other three samples show similar values in electrical conductivity, Seebeck coefficient, and power factor at $600 \mathrm{~K}$ (shown in Fig. 6).

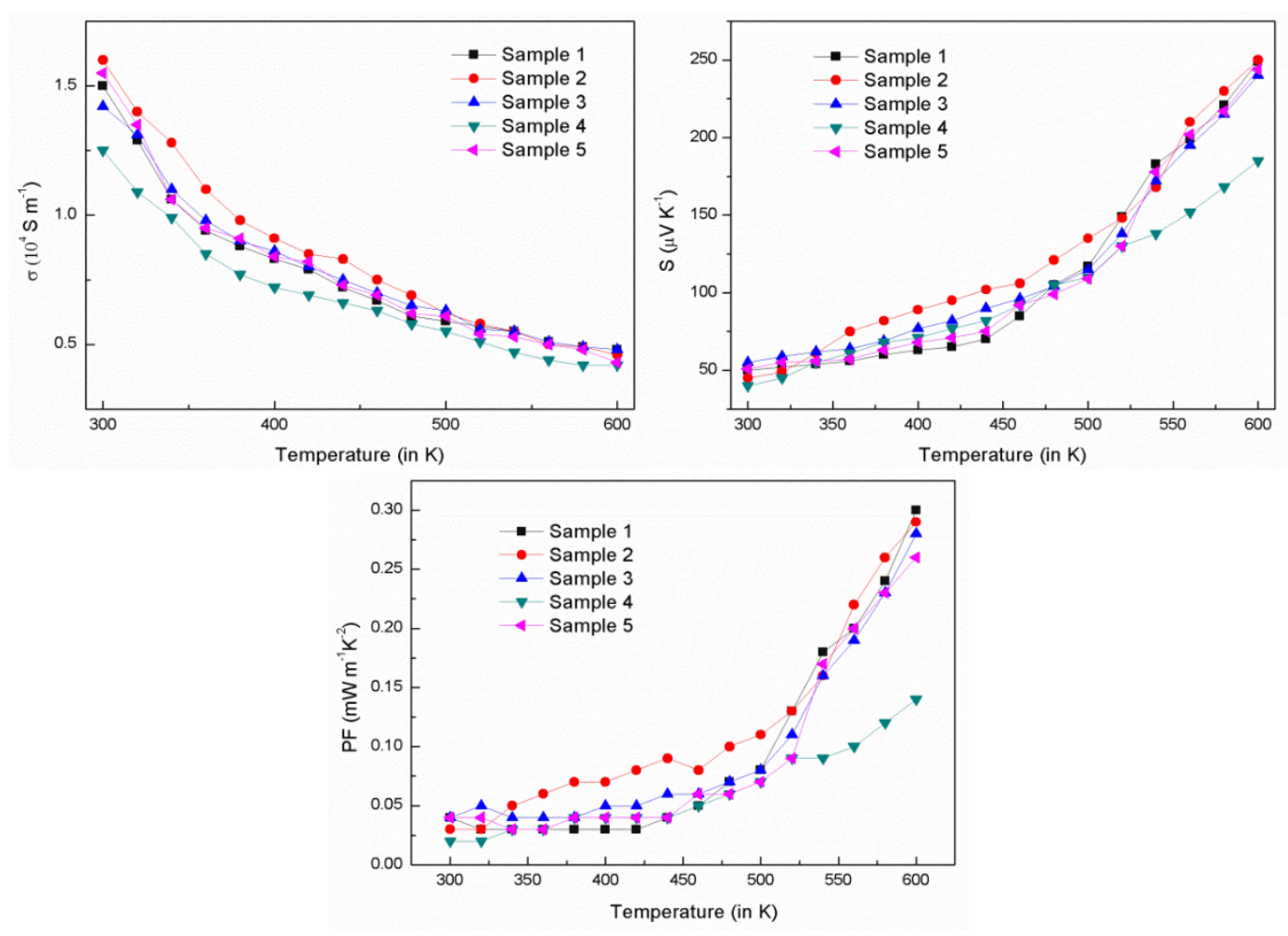

FIG. 6. Temperature dependence of thermal conductivity, Seebeck coefficient and power factors of various samples

TABLE 4. Electrical properties of various samples by Hall measurements

\begin{tabular}{|c|c|c|c|}
\hline Sample & Carrier concentration $\left(\mathrm{cm}^{-3}\right)$ & Resistivity $(\Omega, \mathrm{cm})$ & Mobility $\left(\mathrm{cm}^{2} \mathrm{~V}^{-1} \mathrm{~s}^{-1}\right)$ \\
\hline \hline Sample 1 & $1.8 \times 10^{18}$ & 0.21 & 1.01 \\
\hline Sample 2 & $2.2 \times 10^{19}$ & 0.22 & 0.64 \\
\hline Sample 3 & $2.1 \times 10^{19}$ & 0.21 & 0.59 \\
\hline Sample 4 & $1.7 \times 10^{18}$ & 0.24 & 1.20 \\
\hline Sample 5 & $2.0 \times 10^{18}$ & 0.23 & 0.99 \\
\hline
\end{tabular}

Table 4 presents the electrical properties of CZTSe materials characterized by four probe Hall measurements at room temperature. The measurements were used to estimate the mobility, carrier concentration and resistivity of the materials. All materials had p-type conductivity based on the positive sign of the Hall coefficient. Carrier concentration was found in the range of $10^{18}-10^{19} \mathrm{~cm}^{-3}$. There was an increment in carrier concentration with the increase in Se concentration while resistivity and mobility values decreased i.e. the trend of change in mobility and resistivity with increase in Se content was opposite to the carrier concentration. Since there are some binary and ternary compounds in the samples; these compounds cause a decrease of the carrier concentration. Decrease in mobility could be related to increase in grain size. Moreover the electrical properties were in good agreement with the reports published earlier for kesterite materials. 


\section{Conclusions}

Despite the challenging objective, CZTSe bulk materials were prepared by solid state reaction of the elemental constituents. The structure, morphology, thermoelectric and electrical properties were investigated. Analysis of AFM images revealed a significant difference has been observed in roughness parameters and grain size with respect to $\mathrm{Cu} / \mathrm{Zn}$ variations, and it can be concluded that $\mathrm{Cu}$ deficiency and excess of $\mathrm{Zn}$ in the samples caused a decrease in mean grain size with respect to perfect stoichiometric sample of CZTSe. These observations have been analyzed and verified in terms of XRD and Raman scattering studies. The appearance of prominent peaks in the XRD spectrum confirms the formation of nanocrystalline CZTSe materials. Raman spectra of various samples have the vibration mode peaks corresponding to CZTSe, revealing no secondary phases in the materials. XPS analysis of all the samples confirmed the chemical valences of $+1,+2,+4$, and -1 for $\mathrm{Cu}, \mathrm{Zn}, \mathrm{Sn}$, and $\mathrm{Se}$, respectively.The stoichiometric sample, $\mathrm{Cu}_{2} \mathrm{ZnSnSe}_{4}$, exhibited the maximum power factor $0.30 \mathrm{~mW} \cdot \mathrm{m}^{-1} \mathrm{~K}^{-2}$, having a carrier concentration in the range of $10^{18}-10^{19} \mathrm{~cm}^{-3}$ and resistivity in the range of 0.21 to $0.24 \Omega \cdot \mathrm{cm}$. The electrical and thermoelectric behaviors shown by various samples arein accordance with earlier studies.

\section{Acknowledgements}

Author is sincerely thankful to Director and Dr. Jasaram, Defence Laboratory, Jodhpur; Director, MRC, MNIT, Jaipur; Dr. A. K. Sinha, Dr. M. K. Tiwari, Dr. V. Srihari (beam time for XRD at BL-11) and U. Gautam (beam time for BL-14) at INDUS-II, Raja Rammanna Center for Advanced Technology (RRCAT), Indore; Dr. K. Ashokan and Sh. R. C. Meena from IUAC, New Delhi for their experimental and technical support.

\section{References}

[1] Kush P., Deka S. Multifunctional copper-based quaternary chalcogenide semiconductors toward state-of-the-art energy applications. Chem. Nano Mat., 2019, 5 (4), P. 373-402.

[2] Tanaka K., Oonuki M., Moritake N., Uchiki H. $\mathrm{Cu}_{2} \mathrm{ZnSnS}_{4}$ thin film solar cells prepared by Non-vacuum Processing. Sol. Energy Mater. Sol. Cells, 2009, 93, 583.

[3] Guo Q., Ford G.M., et al. Fabrication of 7.2\% Efficient CZTSSe Solar Cells using CZTS Nanocrystals. J. Am. Chem. Soc., 2010,132 , 17384.

[4] Tsuji I., Shimodaira Y., et al. Novel Stannite-type Complex Sulfide Photocatalysts AI-Zn-AIV-S4 (AI = Cu and Ag; AIV = Sn and Ge) for Hydrogen Evolution under Visible-Light Irradiation. Chem. Mater, 2010, 22, 1402.

[5] Samanta L.K., Bhar G.C. Optical Nonlinearity of Some Stannite and Famatinite Crystals. Phys. Status Solidi A, $1977,41,331$.

[6] Chen S., Gong X.G., et al. Band Structure Engineering of Multinary Chalcogenide Topological Insulators. Phys. Rev. B, $2011, \mathbf{8 3}, 245202$.

[7] Fries T., Shapira Y., et al. Magnetic ordering of the antiferromagnet $\mathrm{Cu}_{2} \mathrm{MnSnS}_{4}$ from magnetization and neutron-scattering measurements. Phys. Rev. B, 1997, 56, 5424.

[8] Nenert G., Palstra T.T.M. Magnetoelectric and Multiferroic Properties of Ternary Copper Chalcogenides Cu 2 MIIMIVS $_{4}$. J. Phys.: Cond. Matter, 2009, 21, 176002.

[9] Liu M.L., Huang F.Q., Chen L.D., Chen I.W. A wide-band-gap P-type thermoelectric material based on quaternary chalcogenides of $\mathrm{Cu}_{2} \mathrm{ZnSnQ}_{4}(\mathrm{Q}=\mathrm{S}, \mathrm{Se})$. Appl. Phys. Lett., 2009, 94, 202103.

[10] Ibanez M., Cadavid D., et al. Composition control and thermoelectric properties of quaternary chalcogenide nanocrystals: The case of Stannite $\mathrm{Cu}_{2} \mathrm{CdSnSe}_{4}$. Chem. Mater, 2012, 24,562.

[11] Dong Y., Khabibullin A.R., et al. Synthesis, Transport properties, and Electronic Structure of $\mathrm{Cu}_{2} \mathrm{CdSnTe}_{4}$. Appl. Phys. Lett., 2014, 104, 252107.

[12] Dong Y., Wang H., Nolas G.S. Synthesis and thermoelectric properties of Cu excess $\mathrm{Cu}_{2} \mathrm{ZnSnSe}_{4}$. Phys. Status Solidi RRL, $2014, \mathbf{8}$, 61.

[13] Wang B., Xiang H., et al. Theoretical investigation on thermoelectric properties of Cu-based chalcopyrite compounds. Phys. Rev. B, 2017, 95, 035201.

[14] Raju C., Falmbigl M., et al. Thermoelectric properties of chalcogenide based $\mathrm{Cu}_{2+x} \mathrm{ZnSn}_{1-x} \mathrm{Se}_{4}$. AIP Adv., $2013,3,032106$.

[15] Yang H., Jauregui L.A., et al. Nontoxic and abundant copper zinc tin sulfide nanocrystals for potential high-temperature thermoelectric energy harvesting. Nano Lett., 2012, 12, 540.

[16] Fan F.J., Wang Y.X., et al. Large-scale colloidal synthesis of non-stoichiometric $\mathrm{Cu}_{2} \mathrm{ZnSnSe}_{4}$ nanocrystals for thermoelectric applications. Adv. Mater., 2012, 24, 6158.

[17] Liu M.L., Chen I.W., Huang F.Q., Chen L.D. Improved thermoelectric properties of Cu-doped quaternary chalcogenides of Cu${ }_{2}$ CdSnSe 4 . Adv. Mater., 2009, 21, 3808.

[18] Ibáñez M., Cadavid D., et al. Composition control and thermoelectric properties of quaternary chalcogenide nanocrystals: The case of stannite $\mathrm{Cu}_{2} \mathrm{CdSnSe}_{4}$. Chem. Mater, 2012, 24, 562.

[19] Fan F.J., Yu B., et al. Colloidal synthesis of $\mathrm{Cu}_{2} \mathrm{CdSnSe}_{4}$ nanocrystals and hot-pressing to enhance the thermoelectric figure-of-merit. J. Am. Chem. Soc., 2011, 133, 15910.

[20] Paul S., Gulyas I., et al. Carrier transport properties in a thin-film $\mathrm{Cu}_{2} \mathrm{ZnSnSe}_{4}$ solar cell. Thin Solid Films, $2019,675,103$.

[21] Zeier W.G., LaLonde A., et al. Influence of a nano phase segregation on the thermoelectric properties of the p-Type doped stannite compound $\mathrm{Cu}_{2+x} \mathrm{Zn}_{1-x} \mathrm{GeSe}_{4}$. J. Am. Chem. Soc., 2012, 134, 7147.

[22] Goto Y., Naito F., et al. Enhanced thermoelectric figure of merit in stannite-kuramite solid solutions $\mathrm{Cu}_{2+x} \mathrm{Fe}_{1-x} \mathrm{SnS}_{4-y}(x=0-1)$ with anisotropy lowering. Inorg. Chem., 2013, 52, 9861.

[23] Dong Y., Wang H.S., Nolas G. Synthesis and thermoelectric properties of Cu excess $\mathrm{Cu}_{2} \mathrm{ZnSnSe}_{4}$. Phys. Status Solidi RRL, $2014, \mathbf{8}, 61$.

[24] Chiang M.H., Fu Y.S., et al. Effects of Zn precursors on solvothermal synthesis of $\mathrm{Cu}_{2} \mathrm{ZnSnSe}_{4}$ nanocrystals. Mater. Lett., 2012 , 83, 192. 
[25] Shi X., Xi L., et al. CuSe Bond Network and Thermoelectric Compounds with Complex Diamondlike Structure. Chem. Mater., 2010, 22, 6029.

[26] Cui Y., Deng R., Wang G., Pan D. A general strategy for synthesis of quaternary semiconductor $\mathrm{Cu}_{2} \mathrm{MSnS}_{4}\left(\mathrm{M}^{2} \mathrm{Co}^{2+}, \mathrm{Fe}^{2+}, \mathrm{Ni}^{2+}, \mathrm{Mn}^{2+}\right)$ nanocrystals. J. Mater. Chem., 2012, 22, 23136.

[27] Du Y.F., Zhou W.H., et al. Solvothermal synthesis and characterization of quaternary $\mathrm{Cu}_{2} \mathrm{ZnSnSe}_{4}$ particles. Mater. Sci. Semi. Proced., 2012, 15, 214.

[28] Wei T., Qin Y., et al. Copper chalcogenide thermoelectric materials. Sci. China Mater, 2019, $62,8$.

[29] Fan C.M., Regulacio M.D., et al. Colloidal nanocrystals of orthorhombic $\mathrm{Cu}_{2} \mathrm{ZnGeS}_{4}$ : phase-controlled synthesis, formation mechanism and photocatalytic behaviour. Nanoscale, 2015, 7, 3247.

[30] Wei K., Nolas G.S. Synthesis and Characterization of Nanostructured Stannite $\mathrm{Cu}_{2} \mathrm{ZnSnSe}_{4}$ and $\mathrm{Ag}_{2} \mathrm{ZnSnSe}_{4}$ for Thermoelectric Applications. ACS Appl. Mater. Interfaces, 2015, 7, 9752.

[31] Xue D.J., Jiao F., et al. Synthesis of Wurtzite $\mathrm{Cu}_{2} \mathrm{ZnGeSe}_{4}$ Nanocrystals and their Thermoelectric Properties. Chem. - An Asian J., 2013, 8, 2383.

[32] Shi X.Y., Huang F.Q., Liu M.L., Chen L.D. Thermoelectric properties of tetrahedrally bonded wide-gap stannite compounds $\mathrm{Cu}_{2} \mathrm{ZnSn}_{1 x} \mathrm{In}_{x} \mathrm{Se}_{4}$. Appl. Phys. Lett., 2009, 94, 122103.

[33] Chen D., Zhao Y., et al. Hot-Injection Synthesis of Cu-Doped $\mathrm{Cu}_{2} \mathrm{ZnSnSe}{ }_{4}$ Nanocrystals to Reach Thermoelectric ZT of 0.70 at $450{ }^{\circ} \mathrm{C}$. ACS Appl. Mater. Interfaces, 2015, 7 (44), 24403.

[34] Ritchie C., Chesman A., Jasieniak J., Mulvaney P. Aqueous Synthesis of $\mathrm{Cu}_{2} \mathrm{ZnSnSe}_{4}$ Nanocrystals. Chem. Mater., 2019,31 (6), 2138.

[35] Zoppi G., Forbes I., et al. $\mathrm{Cu}_{2} \mathrm{ZnSnSe}_{4}$ thin film solar cells produced by selenisation of magnetron sputtered precursors. Progress in Photovoltaics: Research and Applications, 2009, 17 (5), 315.

[36] Fan P., Zhao J., et al. Effects of annealing treatment on the properties of CZTSe thin films deposited by RF-magnetron sputtering. Journal of Alloys and Compounds, 2015, 625, 171.

[37] Redinger A., Hönes K., et al. Detection of a ZnSe secondary phase in coevaporated $\mathrm{Cu}_{2} \mathrm{ZnSnSe}_{4}$ thin films. Applied Physics Letters, 2011, 98 (10), 101907.

[38] Gremenok V.F., Juskenas R., et al. Growth and properties of $\mathrm{Cu}_{2} \mathrm{ZnSnSe}$ films on flexible metallic substrates. Proceedings of the 33rd European Photovoltaic Solar Energy Conference and Exhibition, 2017, P. 1081.

[39] Stanchik V., Gremenok V.F., et al. Effects of selenization time and temperature on the growth of $\mathrm{Cu}_{2} \mathrm{ZnSnSe}_{4}$ thin films on a metal substrate for flexible solar cells. Sol. Ener., 2019, 178, 142.

[40] Urazov K.A., Dergacheva M.B., Gremenok V.F., Mit K.A. AFM Investigation of CZTS and CZTSe thin films. Physics, Chemistry And Application Of Nanostructures: Reviews And Short Notes To Nanomeeting, 2017, 406.

[41] Kumar B.R., Rao T.S. AFM Studies on surface morphology, topography and texture of nanostructured zinc aluminum oxide thin films. Digest Journal of Nanomaterials and Biostructures, 2012, 7 (4), 1881.

[42] Sharma Y.C., Prajapat R. Study of mixing behaviour of Cu, Zn, Sn and Se multilayer structure by annealing. Mater. Res. Express, 2019, 6, 086418.

[43] Li J., Ma T., et al. The $\mathrm{Cu}_{2} \mathrm{ZnSnSe}_{4}$ thin films solar cells synthesized by electrodeposition route. Appl. Sur. Sci., $2012,258,6261$.

[44] Wibowo R.A., Kim W.S., et al. Single step preparation of quaternary $\mathrm{Cu}_{2} \mathrm{ZnSnSe}_{4}$ thin films by RF magnetron sputtering from binary chalcogenide targets. J. Phy. Chem. Sol., 2007, 68, 1908.

[45] Farva U., Park C. Quaternary Chalcogenide Nanocrystals: Synthesis of $\mathrm{Cu}_{2} \mathrm{ZnSnSe}_{4}$ by Solid State Reaction and their Thermoelectric Properties. MRS Online Proceedings Library Archive, 2013, 1543, 137.

[46] Bishop D.M., McCandless B.E., et al. Fabrication and electronic properties of CZTSe single crystals. IEEE Journal of Photovoltaics, 2015, 5, 390.

[47] Wibowo R.A., Jung W.H., et al. Crystallization of $\mathrm{Cu}_{2} \mathrm{ZnSnSe}_{4}$ compound by solid state reaction using elemental powders. Materials Chemistry and Physics, 2010, 124, 1006.

[48] Wibowo R.A., Jung W.H., Kim K.H. Synthesis of $\mathrm{Cu}_{2} \mathrm{ZnSnSe} 4$ compound powders by solid state reaction using elemental powders. J. Phy. Chem. Sol., 2010, 71, 1702.

[49] Curé Y., Pouget S., Reita V., Boukari H. $\mathrm{Cu}_{2} \mathrm{ZnSnSe}_{4}$ thin films grown by molecular beam epitaxy. Scripta Materialia, 2017 , 130, 200.

[50] Choubrac L., Lafond A., et al. The stability domain of the selenide kesterite photovoltaic materials and NMR investigation of the Cu/Zn disorder in $\mathrm{Cu}_{2} \mathrm{ZnSnSe}_{4}$ (CZTSe). Phys. Chem. Chem. Phys., 2015, 17, 15088.

[51] Gurieva G., Levcenco S., et al. Investigation of Detection Limits of $\mathrm{ZnSe}$ and $\mathrm{Cu}_{2} \mathrm{SnSe}_{3} \mathrm{Secondary} \mathrm{Phases} \mathrm{in} \mathrm{Cu}_{2} \mathrm{ZnSnSe}_{4}$. Physica Status Solidi C, 2017, 14, 1700166.

[52] Jagannath, Goutam U.K., et al. HAXPES beamline PES-BL14 at the Indus-2 synchrotron radiation source. J. Synchrotron Rad., 2018, 25, P. $1541-1547$. 